\title{
Genome-wide investigation of aromatic acid transporters in Corynebacterium glutamicum
}

\begin{abstract}
Correspondence
Shuang-Jiang Liu

liusj@sun.im.ac.cn
\end{abstract}

Received 15 September 2006

Revised 14 November 2006

Accepted 16 November 2006

\author{
Muhammad Tausif Chaudhry, ${ }^{1,2}$ Yan Huang, ${ }^{1,2}$ Xi-Hui Shen, ${ }^{1}$ \\ Ansgar Poetsch, ${ }^{3}$ Cheng-Ying Jiang ${ }^{1}$ and Shuang-Jiang Liu ${ }^{1}$ \\ ${ }^{1}$ State Key Laboratory of Microbial Resources, Institute of Microbiology, Chinese Academy of \\ Sciences, Beijing, 100080, China \\ ${ }^{2}$ Graduate University of Chinese Academy of Sciences, Beijing, 100049, China \\ ${ }^{3}$ Lehrstuhl für Biochemie der Pflanzen, Ruhr Universität, Bochum, Germany
}

\section{INTRODUCTION}

Membrane transport in bacteria not only maintains a suitable environment inside the cell by regulating entry of essential nutrients into the cytoplasm and extrusion of deleterious substances from the cell, but also enhances communication between cell and environment (Mitchell, 1967). Membrane proteins are the main players in this transport. Sequencing data from several prokaryotic and eukaryotic genomes have revealed that about $30 \%$ of all the integral membrane proteins are involved in transport across biological membranes (Paulsen et al., 2000).

Among the various categories of transporters classified (Ren et al., 2004), the major facilitator superfamily (MFS; Pao et al., 1998; Saier et al., 1999) is the largest (54 families), best known and functionally the most diverse superfamily of the electrochemical potential-driven transporter subclass. Recently, the structures and functions of three MFS

Abbreviations: AAHS, aromatic acid: $\mathrm{H}^{+}$symporter; MFS, major facilitator superfamily. transporters have been studied in detail (Hirai et al., 2002; Abramson et al., 2003; Huang et al., 2003). The aromatic acid $: \mathrm{H}^{+}$symporter (AAHS) family of the MFS presently contains six members, namely PcaK of Pseudomonas putida (Nichols \& Harwood, 1997), TfdK of Ralstonia eutropha (Leveau et al., 1998), BenK, VanK and MucK of Acinetobacter sp. ADP1 (Collier et al., 1997; Williams \& Shaw, 1997; D'Argenio et al., 1999) and MhpT of Escherichia coli, which are all from Gram-negative bacteria.

Corynebacterium glutamicum is a Gram-positive, nonpathogenic, non-motile, aerobic, coryneform bacterium with a high $\mathrm{G}+\mathrm{C}$ content that belongs to the actinomycetes subphylum (Stackebrandt et al., 1997). Since its isolation (Kinoshita et al., 1957), C. glutamicum has been extensively employed for industrial scale production of amino acids (Lglutamate, L-lysine, etc.), vitamins (D-pantothenic acid, etc.) and nucleotides, and is among the most important microorganisms for industrial biotechnology. The accessibility of genome data for C. glutamicum (Ikeda \& Nakagawa, 2003; Kalinowski et al., 2003) has greatly stimulated studies that use C. glutamicum as a model microorganism in genetic 
and physiological research. Recent studies have demonstrated that C. glutamicum can degrade various aromatic compounds (Shen et al., 2004, 2005a; Shen \& Liu, 2005), and a novel mycothiol-dependent gentisate pathway has been identified (Feng et al., 2006). Although transport systems for amino acids (Simic et al., 2001; Kennerknecht et al., 2002; Eggeling \& Sahm, 2003; Ren et al., 2004) and sugars (Dominguez \& Lindley, 1996; Dominguez et al., 1998; Gourdon et al., 2003) have been well characterized in $C$. glutamicum, knowledge of aromatic compound transport is very limited. In this study, the entire genome of $C$. glutamicum ATCC 13032 was searched for aromatic acid transporter genes and six putative genes encoding transporters were identified through genetic disruption/complementation and uptake assays for various aromatic compounds.

\section{METHODS}

Bacterial strains, plasmids and culture conditions. Bacterial strains and plasmids used in this study are listed in Table 1. E. coli strains were grown in Luria-Bertani (LB) broth on a rotary shaker (150 r.p.m.) or on LB plates containing $1.5 \%(\mathrm{w} / \mathrm{v})$ agar, at $37^{\circ} \mathrm{C}$. C. glutamicum strains were routinely cultivated in LB broth or BHIS (brain heart infusion broth supplemented with $50 \mathrm{mM}$ sorbitol). To test their ability to grow on various aromatic compounds, wild-type C. glutamicum and mutants were inoculated into minimal medium (MM, pH 9.0; Konopka, 1993). Yeast extract (0.1 g per litre) was added to meet the vitamin requirements of bacterial strains. Benzoate, protocatechuate and vanillate were autoclaved in $\mathrm{MM}$ broth. Stock solutions of gentisate $(100 \mathrm{mM})$, resorcinol $(200 \mathrm{mM})$, 3-hydroxybenzoate $(100 \mathrm{mM})$ and 4-hydroxybenzoate (100 mM) were sterilized by filtration through $0.2 \mu \mathrm{m}$ pore size filters and were added to $\mathrm{MM}$ at final concentrations of $2 \mathrm{mM}$. All the C. glutamicum strains were grown with rotary shaking at 150 r.p.m. at $30^{\circ} \mathrm{C}$. Growth was monitored by measuring turbidity at $600 \mathrm{~nm}\left(\mathrm{OD}_{600}\right)$. For selection of mutants, in accordance with the vector used, antibiotics were added at the following concentrations: ampicillin, $100 \mu \mathrm{g} \mathrm{ml}^{-1}$ for E. coli; chloramphenicol, $20 \mu \mathrm{g} \mathrm{ml}^{-1}$ for E. coli and $10 \mu \mathrm{g} \mathrm{ml}^{-1}$ for C. glutamicum; kanamycin, $50 \mu \mathrm{g} \mathrm{m}^{-1}$ for E. coli and $25 \mu \mathrm{g} \mathrm{ml}^{-1}$ for C. glutamicum; nalidixic acid, $50 \mu \mathrm{g} \mathrm{ml}^{-1}$ for $C$. glutamicum.

DNA manipulation and cloning of transporter genes. Genomic DNA of C. glutamicum was isolated by the method of Tauch et al. (1995). DNA manipulation, plasmid isolation and agarose gel electrophoresis were routinely carried out using standard methods (Sambrook et al., 1989). Restriction endonucleases, ligase and DNA polymerase were used according to the manufacturer's instructions. Vectors were electroporated into E. coli and C. glutamicum by the methods of Tauch et al. (2002). Primers used in this work for amplification of intact and disrupted genes are listed in Table 2. To facilitate cloning, both forward and reverse primers were flanked with cleavage sites for restriction endonucleases. PCR consisted of 30 cycles of denaturation at $95^{\circ} \mathrm{C}$ for $1 \mathrm{~min}$, annealing at $42{ }^{\circ} \mathrm{C}$ for $1 \mathrm{~min}$ and extension at $72^{\circ} \mathrm{C}$ for $1.5 \mathrm{~min}$ followed by a final extension at $72{ }^{\circ} \mathrm{C}$ for $10 \mathrm{~min}$. Amplified DNA was analysed by electrophoresis using $1 \%$ agarose, purified by extraction from the gel, restricted with the corresponding endonucleases to obtain the disrupted gene, and finally ligated with pGEM-T Easy vector (Promega).

Disruption of transporter genes in C. glutamicum. For gene disruption, plasmids pK18mobsacBAncgl1031, pK18mobsacBAncgl2302,
pK18mobsacB $4 n c g l 2325$, pK18mobsacBAncgl2326 and pK18mobsacB$\Delta n c g l 2953$ were constructed. All pK18mobsacB derivatives were constructed by ligation of the appropriate disrupted gene (restricted from pGEM-T Easy) with pK18mobsacB. Plasmids were electroporated into C. glutamicum RES167 competent cells. Integration of introduced plasmids into the chromosome by first crossover was selected on BHIS plates containing kanamycin $\left(25 \mathrm{mg} \mathrm{ml}^{-1}\right)$ and nalidixic acid $\left(50 \mathrm{mg} \mathrm{ml}^{-1}\right)$. These antibiotic-resistant cells were grown overnight in LB medium and spread on LB plates containing $10 \%(\mathrm{w} / \mathrm{v})$ sucrose. The second crossover of chromosomal DNA led to kanamycin-sensitive $\left(\mathrm{Km}^{\mathrm{S}}\right)$ cells that were tested for their ability to grow in MM supplemented with aromatic compounds (benzoate, 3-hydroxybenzoate, 4-hydroxybenzoate, gentisate, protocatechuate, resorcinol and vanillate) as sole carbon and energy sources. Mutant strains that were unable to grow on a particular aromatic acid were tested for gene deletion by PCR amplification using the same primers as used for amplification of intact genes. The knockout mutants were desig-

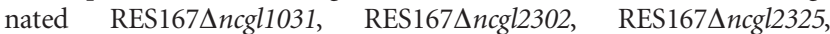

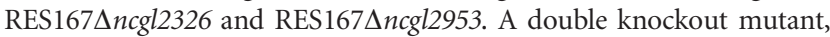
RES167Ancgl(2325-2326), was also constructed by disrupting both $n c g l 2325$ and ncgl2326. The deletion of target genes in pK18mobsacB derivatives and in C. glutamicum mutants was also confirmed by DNA sequencing.

Genetic complementation. For genetic complementation, ncgl2031, ncgl2302, ncgl2325, ncgl2922 and ncgl2953 were amplified by PCR. The native ribosome-binding site (RBS) was replaced with the consensus RBS sequence identified by Amador et al. (1999). The endonuclease-digested PCR product was ligated into E. coli-C. glutamicum shuttle expression vector pXMJ19 (Jakoby et al., 1999) restricted with the appropriate endonucleases. These complementation plasmids were introduced into C. glutamicum RES167 mutants by electroporation to produce complemented strains.

Determination of growth rates of two mutants for benzoate transport at different benzoate concentrations. In order to differentiate the function of the two benzoate transporters, mutants

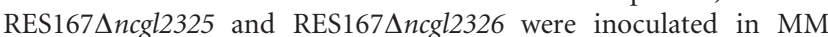
$(\mathrm{pH} 9.0)$ containing different benzoate concentrations (1-5 mM). Triplicate cultures were incubated using a rotary shaker (150 r.p.m.) at $30{ }^{\circ} \mathrm{C}$. Growth was measured by the increase in $\mathrm{OD}_{600}$ and growth rates for the two mutants at different benzoate concentrations were determined.

Assay for uptake of aromatic acids by resting cells. C. glutamicum RES167 and the mutant strains were grown in $100 \mathrm{ml} \mathrm{MM}$ ( $\mathrm{pH}$ 9.0) supplemented with $40 \mathrm{mM}$ sodium acetate to an $\mathrm{OD}_{600}$ of 2.0. Cultures were centrifuged at 8000 r.p.m. for $5 \mathrm{~min}$ at $4{ }^{\circ} \mathrm{C}$ and washed twice with $50 \mathrm{mM}$ phosphate buffer $(\mathrm{pH} 8.0)$. Cells were resuspended in the same buffer and incubated at $30{ }^{\circ} \mathrm{C}$ for $30 \mathrm{~min}$ to exhaust all endocellular carbon reserves. Cells were again centrifuged, washed and resuspended (at $\mathrm{OD}_{600} 2.0$ ) in $50 \mathrm{ml}$ phosphate buffer ( $\mathrm{pH} 8.0$ ) containing $2 \mathrm{mM}$ aromatic acid as substrate. Uptake of aromatic acids, as indicated by the decrease in their concentrations in the supernatant, was analysed by HPLC in a 1050 Hewlett Packard chromatograph equipped with a reverse-phase RP-18 column $(4.6 \mathrm{~mm} \times 240 \mathrm{~mm} \times 0.5 \mathrm{~mm})$ and a photodiode array detector. Standards were prepared in phosphate buffer $(\mathrm{pH} \mathrm{8.0)}$. Aqueous solvent contained $20 \%(\mathrm{v} / \mathrm{v})$ methanol in $100 \mathrm{mM}$ ammonium acetate buffer ( $\mathrm{pH} 4.2)$. Benzoate, 4-hydroxybenzoate and vanillate were typically eluted and monitored with this system at $7.9 \mathrm{~min}$ and $225 \mathrm{~nm}$, at $6.0 \mathrm{~min}$ and $250 \mathrm{~nm}$, and at $7.1 \mathrm{~min}$ and $253 \mathrm{~nm}$, respectively.

Sequence data analysis. The nucleotide sequence of C. glutamicum ATCC 13032 genome was obtained from GenBank (accession no. NC003450; Ikeda \& Nakagawa, 2003). Sequence comparisons and protein sequence similarity searches were performed using 
Table 1. Bacterial strains and plasmids

\begin{tabular}{|c|c|c|}
\hline Strain or plasmid & Relevant characteristic $(s)^{\star}$ & Source or reference \\
\hline \multicolumn{3}{|l|}{ E. coli } \\
\hline XL-1 Blue & $\begin{array}{l}\text { recA1 endA1 gyrA96 thi-1 hsdR17 supE44 relA1 lac }\left(\mathrm{F}^{\prime} \text { proAB }\right. \\
\left.\text { lacl }^{\mathrm{q}} \mathrm{Z} \Delta \mathrm{M} 15 \operatorname{Tn} 10\left(\text { Tet }^{\mathrm{r}}\right)\right)\end{array}$ & $\begin{array}{l}\text { Stratagene } \\
\text { (cat. no. 200228) }\end{array}$ \\
\hline JM109 & $\begin{array}{l}\text { e14- }\left(\mathrm{mcr}^{-}\right) \text {recA1 endA1 gyrA96 thi-1 hsdR17 }\left(\mathrm{r}_{\mathrm{k}}^{-} \mathrm{m}_{\mathrm{k}}^{+}\right) \text {supE44 } \\
\text { relA1 } \mathrm{D}(\text { lac-proAB })\left(\mathrm{F}^{\prime} \text { traD36 proAB lac }{ }^{\mathrm{q}} \mathrm{Z \Delta M} 15\right)\end{array}$ & $\begin{array}{l}\text { Stratagene } \\
(\text { cat. no. 200235) }\end{array}$ \\
\hline \multicolumn{3}{|l|}{ C. glutamicum } \\
\hline RES167 & Restriction-deficient mutant of ATCC 13032, $\Delta(c g l I M-c g l I R-c g l I I R)$. & Tauch et al. (2002) \\
\hline RES167Ancgl1031 & Fragment of DNA encoding amino acids $22-126$ of $n c g l 1031$ deleted & This study \\
\hline 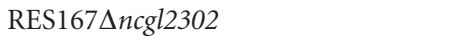 & Fragment of DNA encoding amino acids $76-179$ of $n c g l 12302$ deleted & This study \\
\hline 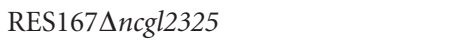 & Fragment of DNA encoding amino acids 239-356 of ncgl2325 deleted & This study \\
\hline 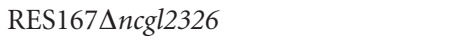 & Fragment of DNA encoding amino acids $215-408$ of $n c g l 2326$ deleted & This study \\
\hline RES167 $\operatorname{ncgl}(2325-2326)$ & $\begin{array}{l}\text { Fragments of DNA encoding amino acids } 239-356 \text { of } n c g l 2325 \text { and } \\
215-407 \text { of } n c g l 2326 \text { deleted }\end{array}$ & This study \\
\hline RES167Ancgl2922 & Fragment of DNA encoding amino acids 111-302 of $n c g l 2922$ deleted & Shen et al. (2005b) \\
\hline RES167 $1 n c g l 2953$ & Fragment of DNA encoding amino acids $174-382$ of $n c g l 2953$ deleted & This study \\
\hline RES167Ancgl1031/pXMJ19-ncgl1031 & RES167Ancgl1031 containing pXMJ19-ncgl1031 & This study \\
\hline RES167Ancgl2302/pXMJ19-ncgl2302 & RES167Ancgl2302 containing pXMJ19-ncgl2302 & This study \\
\hline 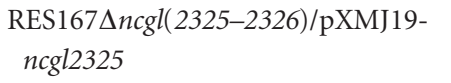 & $\begin{array}{l}\text { Double-knockout strain RES167Ancgl(2325-2326) containing } \\
\text { pXMJ19-ncgl2325 }\end{array}$ & This study \\
\hline 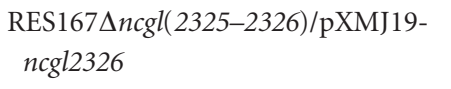 & $\begin{array}{l}\text { Double-knockout strain RES167Ancgl(2325-2326) containing } \\
\text { pXMJ19-ncgl2326 }\end{array}$ & This study \\
\hline \multicolumn{3}{|l|}{ Plasmids } \\
\hline pGEMT-easy & Cloning of PCR products, Amp ${ }^{r}$ & $\begin{array}{l}\text { Promega } \\
\text { (cat. no. A1360) }\end{array}$ \\
\hline pK18mobsacB & $\begin{array}{l}\text { Mobilizable cloning vector, for selecting double crossover in } \\
\text { C. glutamicum, } \mathrm{Km}^{\mathrm{r}}\end{array}$ & Schäfer et al. (1994) \\
\hline pK18mobsacBAncgl1031 & 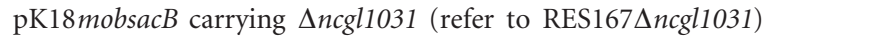 & This study \\
\hline pK18mobsacBAncgl2302 & pK18mobsacB carrying $\Delta n c g l 2302$ (refer to RES167 $\Delta n c g l 2302$ ) & This study \\
\hline pK18mobsacBAncgl2325 & pK18mobsacB carrying $\Delta n c g l 2325$ (refer to RES167 $\Delta n c g l 2325$ ) & This study \\
\hline pK18mobsacBAncgl2326 & pK18mobsacB carrying $\Delta n c g l 2326$ (refer to RES167 $\Delta n c g l 2326)$ & This study \\
\hline pK18mobsacBAncgl2953 & pK18mobsacB carrying $\Delta n c g l 2953$ (refer to RES1674ncgl2953) & This study \\
\hline pXMJ19 & $\begin{array}{l}\text { E. coli-C. glutamicum shuttle vector }\left(\mathrm{Cam}^{\mathrm{r}} \text { Ptac lac }{ }^{\mathrm{q}} \mathrm{pBL} 1 \text { ori } V_{\text {C.g. }} \text {. }\right. \\
\left.\text { pK18ori } V_{\text {E.c. }}\right)\end{array}$ & Jakoby et al. (1999) \\
\hline pXMJ19-ncgl1031 & $\begin{array}{l}\text { pXMJ19 carrying PCR amplified } n c g l 1031 \text { (for complementation } \\
\text { of } \Delta n c g l 1031 \text { ) }\end{array}$ & This study \\
\hline pXMJ19-ncgl2302 & $\begin{array}{l}\text { pXMJ19 carrying PCR amplified } n c g l 2302 \text { (for complementation } \\
\text { of } \Delta n c g l 2302 \text { ) }\end{array}$ & This study \\
\hline pXMJ19-ncgl2325 & $\begin{array}{l}\text { pXMJ19 carrying PCR amplified } n c g l 2325 \text { (for complementation } \\
\text { of } \Delta n c g l 2325 \text { ) }\end{array}$ & This study \\
\hline pXMJ19-ncgl2326 & $\begin{array}{l}\text { pXMJ19 carrying PCR amplified } n c g l 2326 \text { (for complementation } \\
\text { of } \Delta n c g l 2326 \text { ) }\end{array}$ & This study \\
\hline
\end{tabular}

${ }^{\star}$ Abbreviations: E.c., E. coli; C.g., C. glutamicum; Amp, ampicillin; Cam, chloramphenicol; Km, kanamycin.

BLAST programs at the BLAST server of the National Center for Biotechnology Information (http://www.ncbi.nlm.nih.gov). Pairwise and multiple sequence alignments were made with the CLUSTAL $\mathrm{W}$ program (Thompson et al., 1994).

Secondary structure modelling and search for conserved domains and residues. Five topology prediction methods, MEMSAT (Jones et al., 1994), HMMTOP (Tusnády \& Simon,
2001), TMHMM (Krogh et al., 2001; Kyte-Doolittle (Kyte \& Doolittle, 1982; Fariselli et al., 2005) and HTMR (Fariselli et al., 2005) were employed to predict topology of aromatic acid transporters in C. glutamicum and the three well characterized MFS transporters. The domains conserved in MFS transporters (Jessen-Marshall et al., 1995; Pao et al., 1998) and charged amino acid residues conserved in the AAHS family (Ditty \& Harwood, 1999) were located on the basis of predicted secondary structures. 
Table 2. Primers

Underlined sites indicate endonuclease restriction sites added to primers for cloning. The ribosome-binding sites are given in bold.

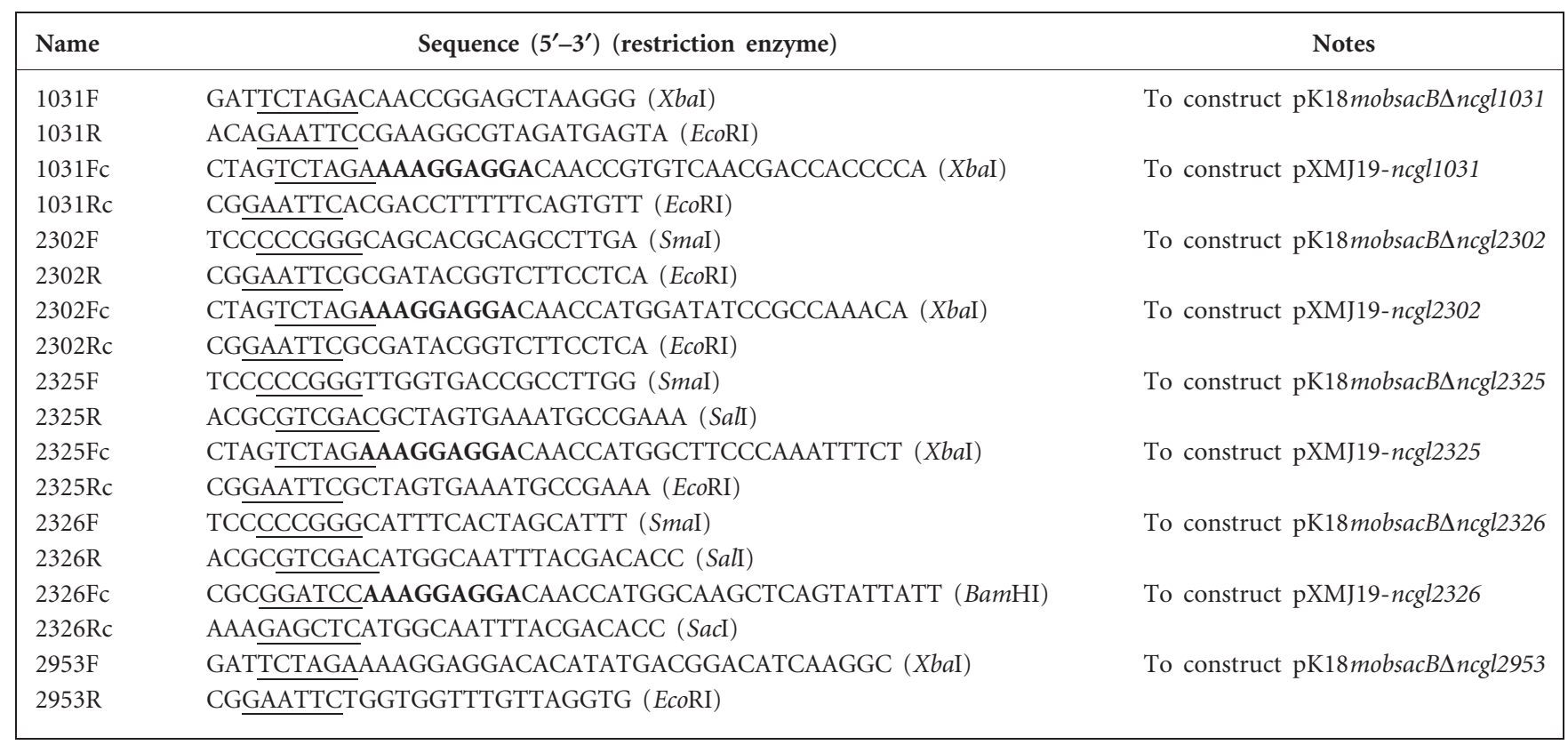

\section{RESULTS}

\section{Genome data mining and identification of $C$. glutamicum genes involved in aromatic acid transport}

According to the publicly available genome sequences of $C$. glutamicum, coding regions for putative membrane proteins represent 19.7-22\% (Ikeda \& Nakagawa, 2003; Kalinowski et al., 2003) of the total coding sequences. Using BLAST searches based on sequence similarities as listed in Table 3, six genes (ncgl1031, ncgl2302, ncgl2325, ncgl2326, ncgl2922 and $n c g l 2953$ ) were identified as encoding putative transport proteins for aromatic acids. The physical map and genetic organization are shown in Fig. 1. Three genes, ncgl2302, $n c g l 2325$ and $n c g l 2326$, are located in the $\beta$-ketoadipate metabolic island, which constitutes almost $1 \%$ of the $C$. glutamicum genome and contains all the genes necessary for catabolism of aromatic compounds via the $\beta$-ketoadipate pathway. In contrast to the location of all necessary genes for the protocatechuate branch of this pathway in the $\beta$ ketoadipate metabolic island, the putative transporter gene, $n c g l 1031$, is located elsewhere in the genome. The ncgl2922 gene is located in another genetic cluster, and this gene has been previously shown to be necessary for 3-hydroxybenzoate and gentisate assimilation (Shen et al., 2005b). The $n c g l 2953$ gene is located in one of the two genetic clusters (ncgl1110-ncgl1113 and ncgl2950-ncgl2953) that have recently been determined to be involved in resorcinol and hydroxyquinol degradation (Huang et al., 2006).

\section{The ncgl1031 ( pcaK) gene is involved in transport of both 4-hydroxybenzoate and protocatechuate}

BLAST search results indicated that NCgl1031 had 31\% and $30 \%$ similarity to 4 -hydroxybenzoate and protocatechuate transporters (PcaK) of Chromobacterium violaceum ATCC 12472 and Burkholderia pseudomallei, respectively. To investigate its function, the ncgl1031 gene was disrupted in C. glutamicum. The resulting mutant, RES167Ancgl1031, had lost the ability to grow with 4hydroxybenzoate and protocatechuate (Fig. 2a) but retained the ability to grow with benzoate and other substituted benzoates. The prevention of mutant growth in the absence of the transporter may possibly be related to the high $\mathrm{pH}$ to which the cells were cultivated. When this mutant was complemented with pXMJ19-ncgl1031, the ability to grow on 4-hydroxybenzoate and protocatechuate was restored (Fig. 2a). This clearly indicated that $n c g l 1031$ is essential for 4-hydroxybenzoate and protocatechuate assimilation in C. glutamicum. Furthermore, assays with resting cells indicated that uptake of 4hydroxybenzoate was active in wild-type RES167 but not in mutant RES167Ancgl1031. Within the first $10 \mathrm{~min}$ of culture the concentration of 4-hydroxybenzoate was halved with wild-type RES167, whereas no significant change in 4hydroxybenzoate was observed with RES167Ancgl1031 (Fig. 3a). Thus, it is concluded that NCgl1031 is a transporter for 4-hydroxybenzoate and protocatechuate in C. glutamicum. 
Table 3. BLAST search results regarding function of genes involved in transport of aromatic acids in C. glutamicum

\begin{tabular}{|c|c|c|c|c|c|c|}
\hline $\begin{array}{l}\text { Gene/ } \\
\text { accession } \\
\text { no. }\end{array}$ & $\begin{array}{l}\text { Position in genome } \\
\text { sequence (nt) }\end{array}$ & $\begin{array}{l}\text { Annotated } \\
\text { function of protein }\end{array}$ & $\begin{array}{l}\text { Identified function } \\
\text { of protein }\end{array}$ & $\begin{array}{c}\text { Calculated } \\
\text { mol. } \\
\text { mass }(\mathrm{Da}) \\
\text { (no. of aa) }\end{array}$ & $\begin{array}{l}\text { Protein with homologous } \\
\text { sequence (organism; accession no.) }\end{array}$ & $\begin{array}{l}\text { Sequence } \\
\text { identity } \\
(\%)\end{array}$ \\
\hline $\begin{array}{l}n c g l 1031 \\
\text { NP600304 }\end{array}$ & $1123531-1124826$ & $\begin{array}{l}\text { 4-Hydroxybenzoate } \\
\text { transporter }\end{array}$ & $\begin{array}{l}\text { 4-Hydroxybenzoate } \\
\text { and protocatechuate } \\
\text { transporter (PcaK) }\end{array}$ & $\begin{array}{l}46008.25 \\
(431)\end{array}$ & $\begin{array}{l}\text { PcaK (Chromobacterium violaceum } \\
\text { ATCC 12472; NP900663) }\end{array}$ & $\begin{array}{r}121 / 381 \\
(31 \%)\end{array}$ \\
\hline \multirow[t]{2}{*}{$\begin{array}{l}n c g l 2302 \\
\text { NP601586 }\end{array}$} & $6527223-2528563$ & Permease of MFS & $\begin{array}{l}\text { Vanillate transporter } \\
\text { (VanK) }\end{array}$ & $\begin{array}{l}46673.86 \\
(446)\end{array}$ & VanK (P. putida; AAL27558) & $\begin{array}{r}185 / 411 \\
(45 \%)\end{array}$ \\
\hline & & & & & VanK (Acinetobacter sp. ADP1; YP045696) & $\begin{array}{r}176 / 411 \\
(42 \%)\end{array}$ \\
\hline \multirow[t]{2}{*}{$\begin{array}{l}n c g l 2326 \\
\text { NP601610 }\end{array}$} & $2554027-2555271$ & $\begin{array}{l}\text { Putative benzoate } \\
\text { membrane } \\
\text { transport protein }\end{array}$ & $\begin{array}{l}\text { Benzoate transporter } \\
\text { (BenE) }\end{array}$ & $\begin{array}{l}42896.80 \\
(414)\end{array}$ & BenE (Rhodococcus sp. RHA1; YP705462) & $\begin{array}{r}205 / 396 \\
(51 \%)\end{array}$ \\
\hline & & & & & $\begin{array}{l}\text { Benzoate membrane transport protein } \\
\text { (Moorella thermoacetica ATCC 39073; } \\
\text { ZP00575807) }\end{array}$ & $\begin{array}{r}128 / 378 \\
(33 \%)\end{array}$ \\
\hline \multirow[t]{2}{*}{$\begin{array}{l}n c g l 2922 \\
\text { NP602219 }\end{array}$} & $3227749-3229083$ & $\begin{array}{l}\text { Putative benzoate } \\
\text { transporter }\end{array}$ & $\begin{array}{l}\text { Gentisate transporter } \\
\text { (GenK) }\end{array}$ & $\begin{array}{l}46803.55 \\
(444)\end{array}$ & BenK (P. putida; AAF63452) & $\begin{array}{r}146 / 401 \\
(36 \%)\end{array}$ \\
\hline & & & & & $\begin{array}{l}\text { Benzoate transport protein } \\
(\text { Pseudomonas sp. ND6; NP943150) }\end{array}$ & $\begin{array}{r}151 / 421 \\
(35 \%)\end{array}$ \\
\hline $\begin{array}{l}n c g l 2953 \\
\text { NP602250 }\end{array}$ & $3258559-3260085$ & Permease of MFS & Unknown & $\begin{array}{l}53704.60 \\
(508)\end{array}$ & $\begin{array}{l}\text { Permease of MFS (Brevibacterium linens } \\
\text { BL2; ZP00381254) }\end{array}$ & $\begin{array}{r}196 / 472 \\
(41 \%)\end{array}$ \\
\hline
\end{tabular}

\section{The ncgl2302 (vanK) gene is involved in transport of vanillate}

The protein encoded by $n c g l 2302$ had $45 \%$ and $42 \%$ similarity with the vanillate transport protein (VanK) of $P$. putida and Acinetobacter sp. ADP1, respectively. Mutant strain RES167Ancgl2302 had lost the ability to grow with vanillate (Fig. 2b) without effects on growth on benzoate, 3and 4-hydroxybenzoate, protocatechuate, gentisate, or resorcinol. After complementation with pXMJ19-ncgl2302, the ability to grow on vanillate was restored (Fig. 1b). Uptake of vanillate by resting cells of wild-type strain RES167 was active, but was inactive in mutant RES167 $n$ ncgl2302 (Fig. 3b). Combining these results, we concluded that $n c g l 2302$ encoded vanillate transporter in $C$. glutamicum.

\section{Both $n c g / 2325$ (benK) and $n c g / 2326$ (benE) are involved in transport of benzoate}

$\mathrm{NCgl} 2325$ and NCgl2326 are active in uptake of benzoate. Both ncgl2325 and ncgl2326 are putative benzoate transporters. NCgl2325 shows $58 \%$ and $55 \%$ similarity with putative benzoate transporters identified from the genomic annotations of Rhodococcus sp. strain 19070 (AAK58907) and Rhodococcus sp. RHA1
(YP702351), respectively. Homologues of NCgl2326 were identified from genomes of Rhodococcus sp. RHA1 (YP705462) and Moorella thermoacetica ATCC 39073 (ZP00575807), but the function of these homologues had not been experimentally characterized. We found that individual disruption of ncgl2325 and ncgl2326 did not result in any phenotypic variation from wildtype in assimilation of aromatic compounds, including benzoate. However, the double-knockout mutant RES167 $\Delta n \operatorname{cgl}(2325-2326)$ lost the ability to grow on benzoate (Fig. 1c, d) but there was no effect on growth on 3- or 4-hydroxybenzoate, protocatechuate, gentisate, resorcinol or vanillate. These results indicated that both $n c g l 2325$ and ncgl2326 are involved in benzoate assimilation and in the absence of either, the other is functional. The involvement of ncgl2325 and ncgl2326 in benzoate assimilation was further confirmed by complementation experiments. When either one of these genes was introduced into the double-knockout mutant using pXMJ19 the ability of the mutants to grow on benzoate was restored (Fig. 1c, d). Results for uptake of benzoate from resting cell assays indicated that there was no uptake by the double knockout mutant RES167 $\Delta$ ncgl(2325-2326); the single knockout mutants RES167Ancgl2325 and RES167 $\Delta n c g l 2326$ retained the ability to take up benzoate, 


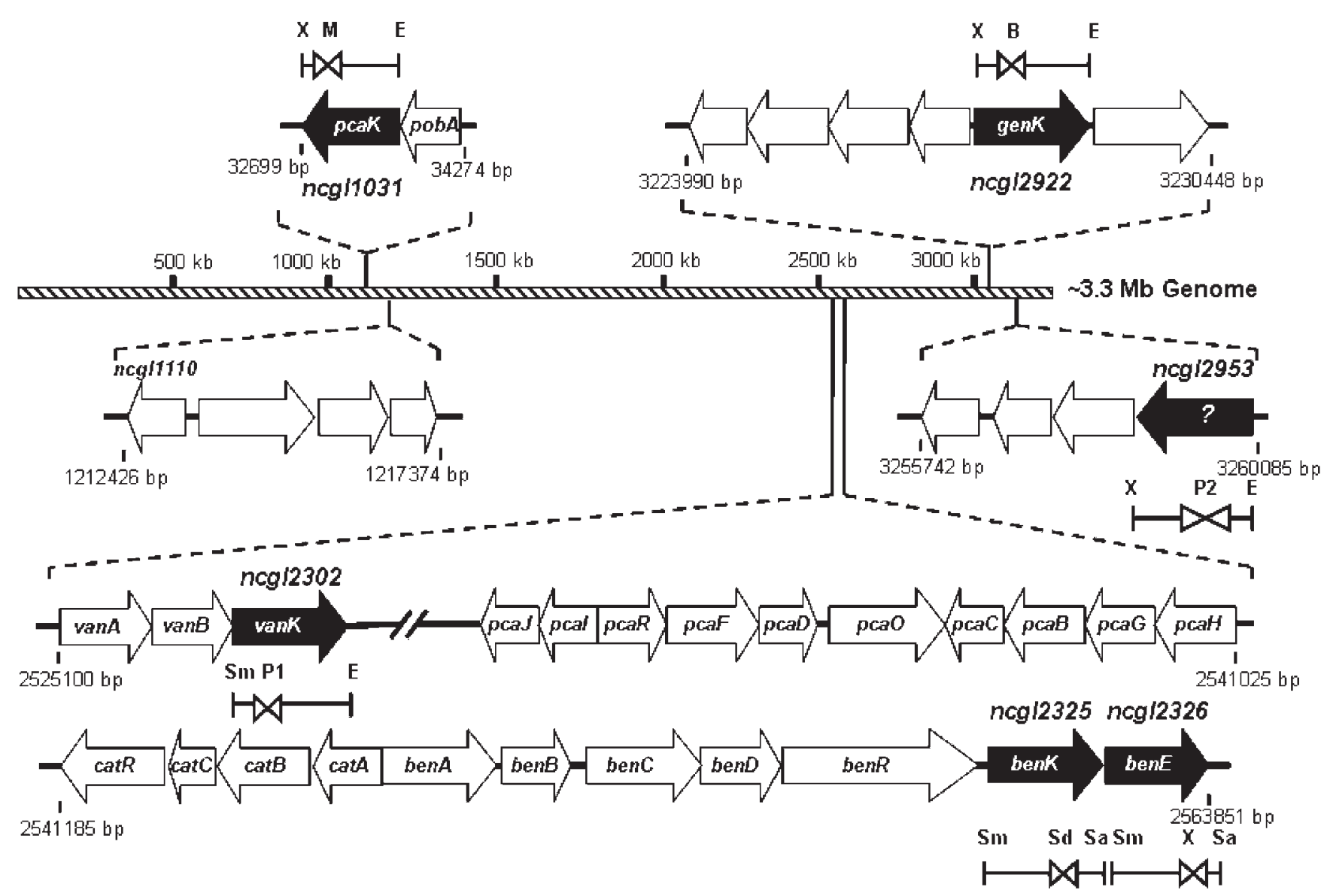

Fig. 1. Physical map and genetic organization of C. glutamicum genes involved in aromatic acid transport in the $\beta$ ketoadipate pathway, gentisate pathway and hydroxyquinol pathway (for details see text). Other genes relevant to these pathways are also shown. Double triangles represent portion of genes enzymically deleted. Restriction sites are indicated as follows: B, BamHI; E, EcoRl; M, Mfel; P1, Pvul; P2, Pvull; Sa, Sall; Sd, Sdul; Sm, Smal; X, Xbal.

and the uptake rates for benzoate in RES167 $\Delta n c g l 2326$ were higher than in RES167 $\Delta n c g l 2325$ (Fig. 3c). It was also observed that the growth rate of RES167Ancgl2326 $\left(0.123 \mathrm{~h}^{-1}\right)$ was higher than that of RES167Ancgl2325 $\left(0.100 \mathrm{~h}^{-1}\right)$.

NCgl2326 (BenE) represents a novel type of benzoate transporter. Sequence alignments and secondary structure prediction revealed that NCgl2325 (BenK), NCgl1031 (PcaK) and NCgl2032 (VanK) all had the typical 12 transmembrane $\alpha$-helices, and had conserved domains at loops 2-3 and 8-9 and conserved charged amino acid residues, characteristic of MFS transporters (Jessen-Marshall et al., 1995; Pao et al., 1998; Ditty \& Harwood, 1999). Strikingly, the transporter encoded by $n c g l 2326$ was predicted to have 11 transmembrane $\alpha$ helices, a structure entirely different from transporters of the MFS, and did not contain any of the above-mentioned conserved features. Since both BenE and BenK are benzoate transporters, alignment of the currently known BenE and BenK sequences (including putative and functionally identified) was performed and results indicated that they formed two clearly separate clusters (Fig. 4). NCgl2326 (BenE) is the first functionally characterized benzoate transporter of its type and was predicted to have 11 helices.

\section{The $n c g / 2953$ gene is not involved in resorcinol and hydroxyquinol transport and its function is still unknown}

As $n c g l 2953$ was located in one of the two genetic clusters encoding the hydroxyquinol pathway in C. glutamicum (Shen et al., 2005a), it was assumed to be involved in transport of related aromatic compounds. Moreover, it shows $41 \%$ similarity with the permease of the MFS in Brevibacterium linens BL2. However, disruption of this gene did not result in any observable phenotypic change regarding assimilation of aromatic compounds as tested in this study. It is thus concluded that $n c g l 2953$ is not involved in aromatic acid transport in the three degradation pathways mentioned earlier. 

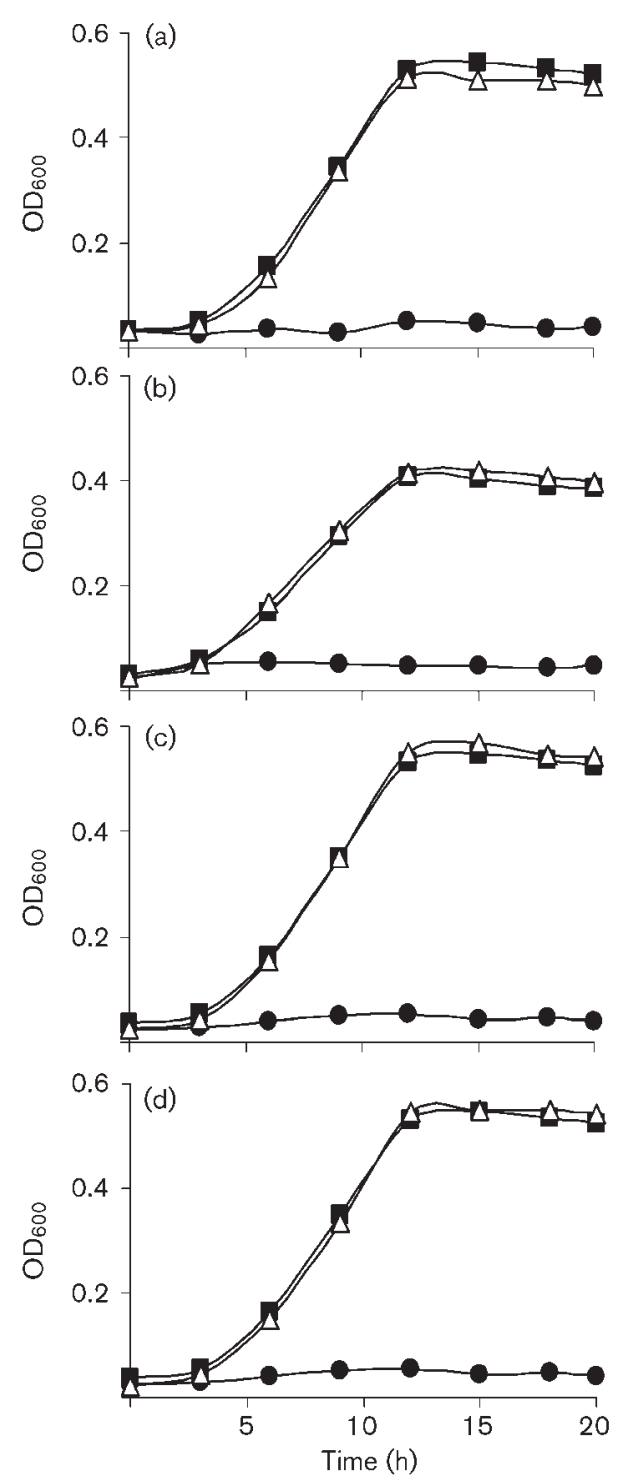

Fig. 2. Phenotypic characterization of various genetically disrupted and complemented strains of C. glutamicum. Data shown here are mean values from triplicates for $\mathrm{OD}_{600}$ values. Growth curves for (a) RES167 Ancg/1031 on 4-hydroxybenzoate (similar results were obtained with protocatechuate),

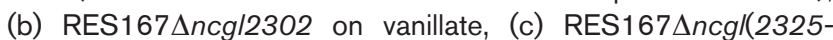
2326) on benzoate, complemented with ncg/2325, (d) RES167 $\mathrm{ncg} /(2325-2326)$ on benzoate, complemented with ncgl2326. - , Parent strain RES167; O, mutant strain; $\triangle$, complemented strain.

\section{DISCUSSION}

Previous studies have shown that C. glutamicum grows on various aromatic compounds and possesses multiple pathways for aromatic compound degradation (Shen et al., 2005a, b), yet how these aromatic compounds enter cells had not been determined. In this study, out of 660 predicted membrane-protein-encoding genes in C. glutamicum (Kalinowski et al., 2003), five genes have been confirmed

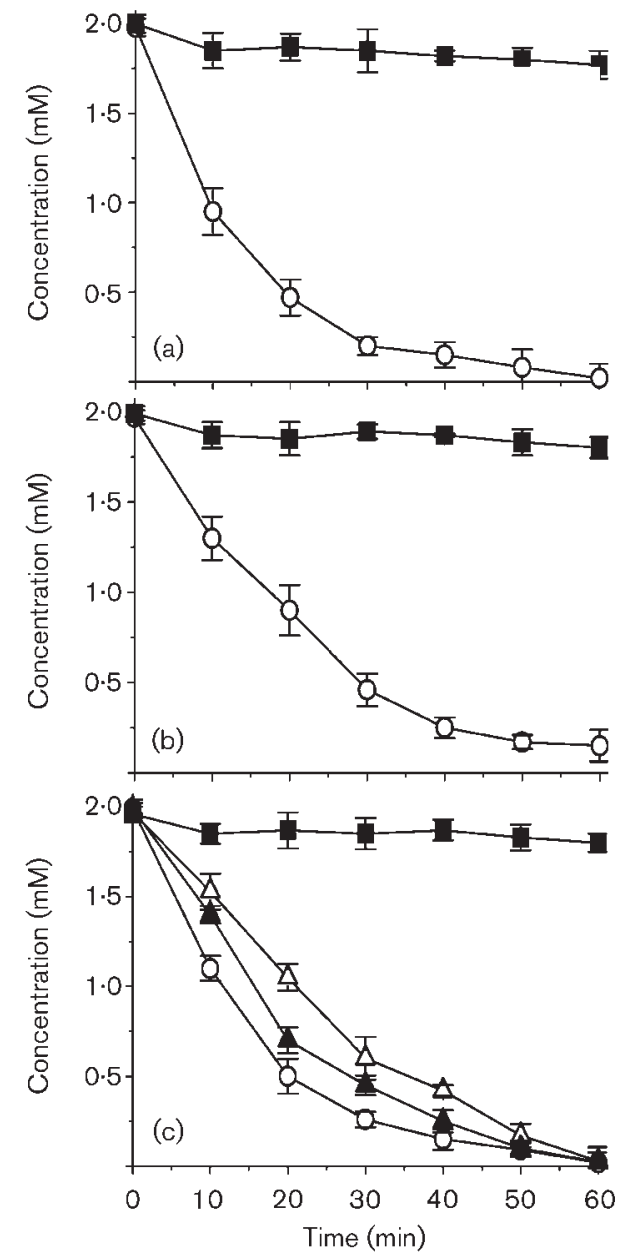

Fig. 3. Resting cell assays for uptake of: (a) 4-hydroxybenzoate ( $\bigcirc$, parent strain RES167; $\mathbf{\square}$, RES1674ncg/1031); (b) vanillate ( $\bigcirc$, parent strain RES167; $\mathbf{\square}$, RES167Ancgl2302); (c) benzoate [O, parent strain RES167; $\triangle$, RES1674ncgl2325;

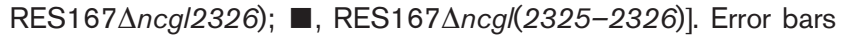
represent standard deviation from the mean of three samples.

to code for aromatic acid transporters. As demonstrated in this study, vanillate is transported via VanK, and VanK in $C$. glutamicum (encoded by ncgl2302) was found to be exclusively responsible for vanillate transport, and was devoid of any involvement in transport of protocatechuate or 4-hydroxybenzoate. This is different from Acinetobacter sp. strain ADP1, in which VanK was reported to be also involved in 4-hydroxybenzoate and protocatechuate transport (D’Argenio et al., 1999). While working on nitrogen metabolism, Merkens et al. (2005) reported that vanK mutation in C. glutamicum led to decreased growth on protocatechuate and thus proposed the occurrence of an additional protocatechuate transporter. We indeed found that NCgl1301 (PcaK) was responsible for protocatechuate and 4-hydroxybenzoate transport in C. glutamicum. However, our results were significantly different from those of Merkens et al. (2005). A similar transporter was 


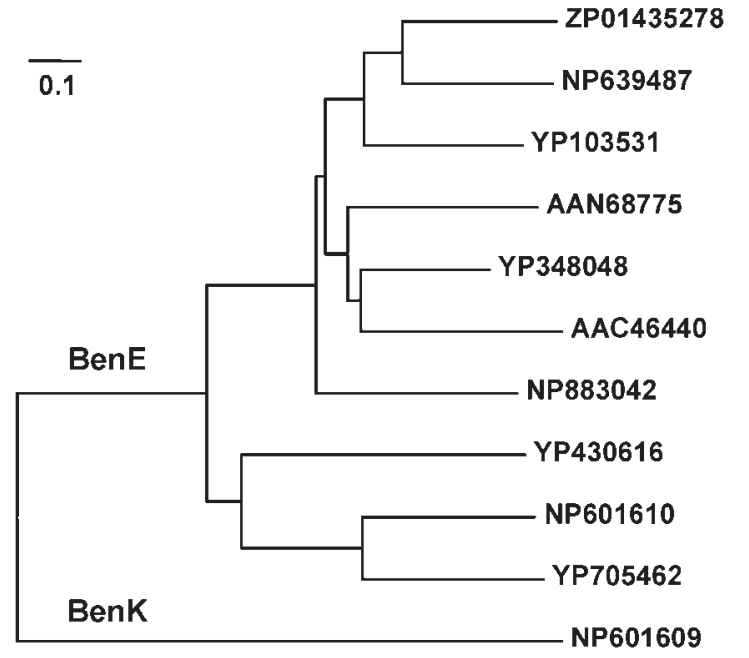

Fig. 4. Phylogenetic relationship of the BenE family of benzoate transporters. Homologues were selected from results of a BLASTP search of GenBank. The phylogenetic tree was constructed using the neighbour joining method (Saitou \& Nei, 1987) and multiple sequence alignment was done using CLUSTAL W (Thompson et al., 1994). The scale bar indicates percentage divergence (distance). The accession numbers (from top to bottom) represent the following species: Shewanella baltica OS195, Xanthomonas campestris pv. campestris str. ATCC 33913, Burkholderia mallei ATCC 23344, P. putida KT2440, P. fluorescens PfO-1, Acinetobacter sp. ADP1, Bordetella parapertussis 12822, Moorella thermoacetica ATCC 39073, C. glutamicum ATCC 13032, Rhodococcus sp. RHA1. BenK of C. glutamicum ATCC 13032 was used as the outgroup.

identified in P. putida (Nichols \& Harwood, 1997); expression of pcaK was repressed by benzoate and preferential degradation of benzoate over 4-hydroxybenzoate was observed (Nichols \& Harwood, 1995).

Two modes have been reported for benzoate transport in bacteria. The first is by simple or facilitated diffusion (Harwood \& Gibson, 1986), and the second by specific membrane transporters (Miguez et al., 1995; Collier et al., 1997). In C. glutamicum this transport is through membrane transporters. In the present research two benzoate transporters, BenK and BenE, have been identified in $C$. glutamicum. It is of most interest that the predicted 11 helix transmembrane protein, NCgl2526 (BenE), is active in benzoate transport. Homologues of BenE were also identified in Agrobacterium tumefaciens, Acinetobacter sp. strain ADP1, Rhodococcus sp. RHA1 and P. putida. In all of these cases, sequence similarities between BenK and BenE are very low, i.e. $15.0 \%$ identity for C. glutamicum, $15.5 \%$ for Ag. tumefaciens strain C58 (accession numbers NP355471 and NP532938), $15.0 \%$ for Acinetobacter sp. strain ADP1 (YP046120 and YP046126), 14.4\% for Rhodococcus sp. RHA1 (YP702351 and YP705462) and $14.0 \%$ for P. putida KT2440 (NP745309 and NP745311).
Further work is needed on characterization of the structurefunction relationship of this novel type of benzoate transporter (BenE) and on comparison of benzoate uptake kinetics between BenK and BenE.

\section{ACKNOWLEDGEMENTS}

This work was supported by grants from the National Natural Science Foundation of China $(20577067,30230010)$.

\section{REFERENCES}

Abramson, J., Smirnova, I., Kasho, V., Verner, G., Kaback, H. R. \& Iwata, S. (2003). Structure and mechanism of the lactose permease of Escherichia coli. Science 301, 610-615.

Amador, E. J., Castro, M., Correia, A. \& Martin, J. F. (1999). Structure and organization of the rrnD operon of Brevibacterium lactofermentum: analysis of $16 \mathrm{~S}$ rRNA gene. Microbiology 145, 915-924.

Collier, L. S., Nichols, N. N. \& Neidle, E. L. (1997). benK encodes a hydrophobic permease-like protein involved in benzoate degradation by Acinetobacter sp. strain ADP1. J Bacteriol 179, 5943-5946.

D’Argenio, D. A., Segura, A., Coco, W. M., Bünz, P. V. \& Ornston, L. N. (1999). The physiological contribution of Acinetobacter PcaK, a transport system that acts upon protocatechuate, can be masked by the overlapping specificity of VanK. J Bacteriol 181, 3505-3515.

Ditty, J. L. \& Harwood, C. S. (1999). Conserved cytoplasmic loops are important for both the transport and chemotaxis functions of PcaK, a protein from Pseudomonas putida with 12 membrane-spanning regions. J Bacteriol 181, 5068-5074.

Dominguez, H. \& Lindley, N. D. (1996). Complete sucrose metabolism requires fructose phosphotransferase activity in Corynebacterium glutamicum to ensure phosphorylation of liberated fructose. Appl Environ Microbiol 62, 3878-3880.

Dominguez, H., Rollin, C., Guyonvarch, A., Guerquin-Kern, J. L., Cocaign-Bousquet, M. \& Lindley, N. D. (1998). Carbon flux distribution in the central metabolic pathways of Corynebacterium glutamicum during growth on fructose. Eur J Biochem 254, 96-102.

Eggeling, L. \& Sahm, H. (2003). New ubiquitous translocators: amino acid export by Corynebacterium glutamicum and Escherichia coli. Arch Microbiol 180, 155-160.

Fariselli, P., Finelli, M., Rossi, I., Amico, M., Zauli, A., Martelli, P. G. \& Casadio, R. (2005). TRAMPLE: the transmembrane protein labeling environment. Nucleic Acids Res 33, W198-W201.

Feng, J., Che, Y., Milse, J., Yin, Y. J., Liu, L., Ruckert, C., Shen, X. H., Qi, S. W., Kalinowski, J. \& Liu, S. J. (2006). The gene ncgl2918 encodes a novel maleylpyruvate isomerase that needs mycothiol as cofactor and links mycothiol biosynthesis and gentisate assimilation in Corynebacterium glutamicum. J Biol Chem 281, 10778-10785.

Gourdon, P., Raherimandimby, M., Dominguez, H., CocaignBousquet, M. \& Lindley, N. D. (2003). Osmotic stress, glucose transport capacity and consequences for glutamate overproduction in Corynebacterium glutamicum. J Biotechnol 104, 77-85.

Harwood, C. S. \& Gibson, J. (1986). Uptake of benzoate by Rhodopseudomonas palustris grown aerobically in light. J Bacteriol 165, 504-509.

Hirai, T., Heymann, J. A. W., Shi, D., Sarker, R., Maloney, P. C. \& Subramaniam, S. (2002). Three-dimensional structure of a bacterial oxalate transporter. Nat Struct Biol 9, 597-600. 
Huang, Y., Lemieux, M. J., Song, J., Auer, M. \& Wang, D. N. (2003). Structure and mechanism of the glycerol-3-phosphate transporter from Escherichia coli. Science 301, 616-620.

Huang, Y., Zhao, K.-X., Shen, X.-H., Chaudhry, M. T., Jiang, C.-Y. \& Liu, S.-J. (2006). Genetic characterization of resorcinol catabolic pathway in Corynebacterium glutamicum. Appl Environ Microbiol 72 $7238-7245$.

Ikeda, M. \& Nakagawa, S. (2003). The Corynebacterium glutamicum genome: features and impacts on biotechnological processes. Appl Microbiol Biotechnol 62, 99-109.

Jakoby, M., Ngouoto-Nkili, C. E. \& Burkovski, A. (1999). Construction and application of new Corynebacterium glutamicum vectors. Biotechnol Techniques 13, 437-441.

Jessen-Marshall, A. E., Paul, N. J. \& Brooker, R. J. (1995). The conserved motif $\operatorname{GXXX}(\mathrm{D} / \mathrm{E})(\mathrm{R} / \mathrm{K}) \mathrm{XG}(\mathrm{X})(\mathrm{R} / \mathrm{K})(\mathrm{R} / \mathrm{K})$, in hydrophilic loop 2/3 of the lactose permease. J Biol Chem 270, 16251-16257.

Jones, D. T., Taylor, W. R. \& Thornton, J. M. (1994). A model recognition approach to the prediction of all-helical membrane protein structure and topology. Biochemistry 33, 3038-3049.

Kalinowski, J., Bathe, B., Bischoff, N., Bott, M., Burkovski, A., Dusch, N., Eggeling, L., Eikmanns, B. J., Gaigalat, L. \& other authors (2003). The complete Corynebacterium glutamicum ATCC 13032 genome sequence and its impact on the production of Laspartate-derived amino acids and vitamins. J Biotechnol 104, 5-25.

Kennerknecht, N., Sahm, H., Yen, M. R., Patek, R., Saier, M. H., Jr \& Eggeling, L. (2002). Export of L-isoleucine from Corynebacterium glutamicum: a two-gene-encoded member of a new translocator family. J Bacteriol 184, 3947-3956.

Kinoshita, S., Udaka, S. \& Shimono, M. (1957). Amino acid fermentation. I. Production of L-glutamic acid by various microorganisms. J Gen Appl Microbiol 3, 193-205.

Konopka, A. (1993). Isolation and characterization of a subsurface bacterium that degrades anilines and methylalanines. FEMS Microbiol Lett 111, 93-99.

Krogh, A., Larsson, B., von Heijne, G. \& Sonnhammer, E. L. L. (2001). Predicting transmembrane protein topology with a hidden Markov model: application to complete genomes. J Mol Biol 305, 567-580.

Kyte, J. \& Doolittle, R. F. (1982). A simple method for displaying the hydropathic character of a protein. J Mol Biol 157, 105-132.

Leveau, J. H. J., Zehnder, A. J. B. \& Van der Meer, J. R. (1998). The $t f d K$ gene product facilitates uptake of 2,4-dichlorophenoxyacetate by Ralstonia eutropha JMP134 (pJP4). J Bacteriol 180, 2237-2243.

Merkens, H., Beckers, G., Wirtz, A. \& Burkovski, A. (2005). Vanillate metabolism in Corynebacterium glutamicum. Curr Microbiol 51, 59-65.

Miguez, C. B., Greer, C. W., Ingram, J. M. \& MacLeod, R. A. (1995). Uptake of benzoic acid and chloro-substituted benzoic acids by Alcaligenes denitrificans BRI 3010 and BRI 6011. Appl Environ Microbiol 61, 4152-4159.

Mitchell, P. (1967). Translocations through natural membranes. $A d v$ Enzymol 29, 33-87.

Nichols, N. N. \& Harwood, C. S. (1995). Repression of 4hydroxybenzoate transport and degradation by benzoate: a new layer of regulatory control in the Pseudomonas putida $\beta$-ketoadipate pathway. J Bacteriol 177, 7033-7040.

Nichols, N. N. \& Harwood, C. S. (1997). PcaK, a high-affinity permease for the aromatic compounds 4-hydroxybenzoate and protocatechuate from Pseudomonas putida. J Bacteriol 179, 5056-5061.

Pao, S. S., Paulsen, I. T. \& Saier, M. H., Jr (1998). Major facilitator superfamily. Microbiol Mol Biol Rev 62, 1-34.
Paulsen, I. T., Nguyen, L., Sliwinski, M. K. \& Saier, M. H., Jr (2000). Microbial genome analyses: comparative transport capabilities in eighteen prokaryotes. J Mol Biol 301, 75-100.

Ren, Q., Kang, K. H. \& Paulsen, I. T. (2004). TransportDB: a rational database of cellular membrane transport system. Nucleic Acids Res 32, D284-D288.

Saier, M. H., Jr, Beatty, J. T., Goffeau, A., Harley, K. T., Heijne, W. H., Huang, S. C., Jack, D. L., Jahn, P. S., Lew, K. \& other authors (1999). The major facilitator superfamily. J Mol Microbiol Biotechnol 64, $354-411$.

Saitou, N. \& Nei, M. (1987). The neighbor-joining method: a new method for reconstructing phylogenetic trees. Mol Biol Evol 4, 406-425.

Sambrook, J., Fritsh, E. F. \& Maniatis, T. (1989). Molecular Cloning: a Laboratory Manual, 2nd edn. Cold Spring Harbor, NY: Cold Spring Harbor Laboratory.

Schäfer, A., Tauch, A., Jager, W., Kalinowski, J., Thierbatch, G. \& Pühler, A. (1994). Small mobilizable multi-purpose cloning vector derived from the Escherichia coli plasmid pK18 and pK19: selection of defined deletions in the chromosome of Corynebacterium glutamicum. Gene 145, 69-73.

Shen, X.-H. \& Liu, S.-J. (2005). Key enzymes of the protocatechuate branch of the $\beta$-ketoadipate pathway for aromatic degradation in Corynebacterium glutamicum. Sci China 48, 241-249.

Shen, X.-H., Liu, Z.-P. \& Liu, S.-J. (2004). Functional identification of the gene locus (ncgl2319) and characterization of catechol 1,2dioxygenase in Corynebacterium glutamicum. Biotechnol Lett 26, 575-580.

Shen, X.-H., Jiang, C.-Y., Huang, Y., Liu, Z.-P. \& Liu, S.-J. (2005a). Functional identification of novel genes involved in the glutathioneindependent gentisate pathway in Corynebacterium glutamicum. Appl Environ Microbiol 71, 3442-3452.

Shen, X.-H., Huang, Y. \& Liu, S.-J. (2005b). Genomic analysis and identification of catabolic pathways for aromatic compounds in Corynebacterium glutamicum. Microbes and Environ 20, 160-167.

Simic, P., Sahm, H. \& Eggeling, L. (2001). L-Threonine export: use of peptides to identify a new translocator from Corynebacterium glutamicum. J Bacteriol 183, 5317-5324.

Stackebrandt, E., Rainey, F. A. \& Ward-Rainey, N. L. (1997). Proposal for a new hierarchic classification system, Actinobacteria classis nov. Int J Syst Bacteriol 47, 479-491.

Tauch, A., Kassing, F., Kalinowski, J. \& Pühler, A. (1995). The Corynebacterium xerosis composite transposon Tn5432 consists of two identical insertion sequences, designated IS1249, flanking the erythromycin resistance gene emrCX. Plasmid 34, 119-131.

Tauch, A., Kirchner, O., Loffler, B., Gotker, S., Pühler, A. \& Kalinowski, J. (2002). Efficient transformation of Corynebacterium glutamicum with a mini-replicon derived from the Corynebacterium glutamicum plasmid pGA1. Curr Microbiol 45, 362-367.

Thompson, J. D., Higgins, D. G. \& Gibson, T. J. (1994), CLUSTAL W: improving the sensitivity of progressive multiple sequence alignment through sequence weighting, position-specific gap penalties and weight matrix choice. Nucleic Acids Res 22, 4673-4680.

Tusnády, G. E. \& Simon, I. (2001). The HMMTOP transmembrane topology prediction server. Bioinformatics 17, 849-850.

Williams, P. A. \& Shaw, L. E. (1997). mucK, a gene in Acinetobacter calcoaceticus ADP1 (BD413) encodes the ability to grow on exogenous cis,cis-muconate as the sole carbon source. J Bacteriol 179, 5935-5942.

Edited by: H. L. Drake 